\title{
Benign Major Salivary Gland Neoplasm
}

National Cancer Institute

\section{Source}

National Cancer Institute. Benign Major Salivary Gland Neoplasm. NCI Thesaurus. Code C4771.

A non-metastasizing neoplasm that arises from the major salivary glands.

Representative examples include Warthin tumor, monomorphic adenoma, and pleomorphic adenoma. 